\title{
VALIDITY AND RELIABILITY OF ARABIC VERSION OF JEBSEN TAYLOR HAND FUNCTION TEST
}

Mahmoud M. Shaaban*; Mohsen M. Elsayad** and Amira H. Draz ***

* B.Sc in Physical Therapy (2013) Cairo University.

** Professor of Physical Therapy, Basic Science Department, Faculty of Physical Therapy, Cairo University, Fr. Dean faculty of physical therapy, Modern

University, Dean collage of Applied sciences, Gulf medical university, Director of biomechanics lab, Wichita state University USA.

*** Professor of Physical Therapy, Basic Science Department, Faculty of Physical Therapy, Cairo University, Dean Faculty of physical therapy, Hertfordshire University.

Key Words: Validity-Reliability-Arabic Jebsen Taylor hand function test.

*E-mail-Shaaban.m@outlook.com

\section{ABSTRACT}

Objective: The purpose of the study is to culturally translate and validate the Arabic version of Arabic Jebsen Taylor hand function test (and evaluate the test-retest reliability, internal consistency, construct validity ceiling or floor effects of this instruments) in normal population to measure the physical function and to ensure better care delivery. Subject and Methods: Two expert panels (each consists of nine experts) and 150 normal population aged from 18 to 60 years old participated in this study. Forward translation, development of preliminary initially translated version, backward translation, and development of the pre-final version and testing of pre-final version using experts then testing of the final version on patients were done. Clarity index, expert proportion of clearance, index of content validity, expert proportion of relevance, descriptive statistics, missed item index, time taken to answer the scale, Cronbach's coefficient alpha and Spearman's rank correlation coefficients were used for statistical analysis. Results: The scale index of clarity equaled $100 \%$, while The scale index of content validity equaled $92.38 \%$. With regard to internal consistency, the Cronbach's alpha equaled 0.598 (range from 0.487 to 0.660 ). In addition, the Spearman's rank correlations were moderate to strong in the majority of items. Conclusion: The Arabic Jebsen Taylor hand function test is a valid and reliable tool and is comparable to the original English version.

\section{INTRODUCTION}

In clinical literature, there are multiple tests for the evaluation of hand function. In spite of their specificity in particular patient populations, the assessment of $\mathrm{ADL}$, as fundamental self -care, remain 
too general and focus on the global functions rather than the specific and function. Moreover, standard performance, such as normative data for comparison of limited and function is absent (Culicchia et al., 2016).

The hand function test of interest; jebsen hand function test (JTHFT)evaluates common aspects of hand function commonly used in ADL (Rhee, Yu and Kim, 2011).It also provides objective measurements of standardized tasks relative to norms. Additionally, it can be used in many local clinical settings and can be administrated in a short time by using readily available materials (Jebsen et al., 1969)

Test-retest reliability was established from the original JTHFT, where results were found to be fairly to moderately consistent over time. In addition, no significant learning effect was found between the two sessions (Jebsen et al., 1969). Several studies also demonstrated that the JHFT had moderate to high test-retest reliability and excellent intra-rater reliability $(\mathrm{r}=0.84$ and $0.85, \mathrm{p}<0.05)$ with absent practice effect $(\mathrm{p}<0.05)$

(Hackel et al., 1992).

Design of the study:

The study was a cross-sectional study that employed simple random sample technique.

\section{Subject (selection of patients):}

Inclusion Criteria

- Subjects age from 20-50, then grouped according to age;(20-29,3039,40-50).

-All the subjects are able to read and write in Arabic.

- Being no handicap.

-Both males and females.

- All the subjects are high education.

\section{Exclusive criteria}

- Subjects were not able to read the questionnaire

- Subjects with handicap,

-Systematic inflammatory rheumatic diseases,

-Neurological conditions,

-Psychiatric disorders.

- History of cerebral concussions, visual or vestibular disorders.

\section{- Assessment scale}

\section{METHODS:}

The JTHFT is a seven-part, timed diagnostic test to evaluate the level of hand function. Each subtest was designed to test each subject in precisely the same manner. The seven subtests include writing, simulated 
page turning, lifting small objects, simulated feeding, stacking, and lifting large, light weight, and heavy objects. The non dominant hand is tested before the dominant hand, and each task is timed by using a stopwatch.

\section{- Procedures}

First the English version of the scale was translated into Arabic independently by two certified independent translator. The two translations translated back to English by a two certified independent translator.

The original and translated English versions were compared, necessary corrections were made, and then final Arabic version was obtained. The sample text was administered to 150 patients to test its understand ability then the scale was administered to 150 patients for reliability to estimate test-retest reliability the same questionnaire was readministered to the same patients after a two-week interval as we did not want the scores to be influenced by changes in symptoms.

\section{MATERIAL}

\section{a) Assessment scale}

Jebsen Taylor Hand Function Test

b) Procedures followed (Sousa and Rojjanasrirat, 2011):

1- Forward translation: Translation of the original JTHFT into Arabic (forward translation or one-way translation):

2- Comparison of the two translated versions of the JTHFT (A1 and A2): synthesis

3- Blind back-translation (blind backward translation or blind double translation) of the preliminary initial translated version of the JTHFT:

4- Comparison of the two back-translated versions of the JTHFT (B1 and B2).

5- Pilot testing of the pre-final Arabic version of the scale for face and content validity.

6- Feasibility (ability to use on larger sample) was evaluated by the assessment of the frequency of missing answers per item and administration time.

\section{RESULTS}

Nine experts and 150 normal people in this study.

The results of this study were presented as follow:

\section{Experts Results:}

-Two experts were of gynecology specialty, four expert was of basic science specialty and one expert was of neurology specialty one was 
orthopedic specialty and one expert physical therapist (20 years' experience).

\section{Clarity index of the final version}

The scale index of clarity equaled $100 \%$ as shown in table (1).

Table (1): Items index of clarity of the final version

\begin{tabular}{|c|c|c|}
\hline Item & Clear Response & Items index of clarity \\
\hline Item (1) & $\mathbf{9}$ & $\mathbf{1 0 0 \%}$ \\
\hline Item (2) & $\mathbf{9}$ & $\mathbf{1 0 0 \%}$ \\
\hline Item (3) & $\mathbf{9}$ & $\mathbf{1 0 0 \%}$ \\
\hline Item (4) & $\mathbf{9}$ & $\mathbf{1 0 0 \%}$ \\
\hline Item (5) & 9 & $\mathbf{1 0 0 \%}$ \\
\hline Item (6) & 9 & $\mathbf{1 0 0 \%}$ \\
\hline Item (7) & 9 & $\mathbf{1 0 0 \%}$ \\
\hline Mean & 9 & $\mathbf{1 0 0 \%}$ \\
\hline
\end{tabular}

a) Expert proportion of clearance of the final version

The mean of proportion of clearance (clear responses) equaled $100 \%$ as shown in table (2).

Table (2): Expert proportion of clearance of the final version

\begin{tabular}{|c|c|c|}
\hline $\begin{array}{c}\text { Expert } \\
\text { number }\end{array}$ & $\begin{array}{c}\text { Number of experts' agreement } \\
\text { (clear responses) }\end{array}$ & Proportion of clearance \\
\hline 1 & 7 & $\mathbf{1 0 0 \%}$ \\
\hline 2 & 7 & $\mathbf{1 0 0 \%}$ \\
\hline 3 & 7 & $\mathbf{1 0 0 \%}$ \\
\hline 4 & 7 & $\mathbf{1 0 0 \%}$ \\
\hline 5 & 7 & $\mathbf{1 0 0 \%}$ \\
\hline 6 & 7 & $\mathbf{1 0 0 \%}$ \\
\hline 7 & 7 & $\mathbf{1 0 0 \%}$ \\
\hline $\mathbf{9}$ & 7 & $\mathbf{1 0 0 \%}$ \\
\hline Mean & 7 & $\mathbf{1 0 0 \%}$ \\
\hline
\end{tabular}

1. Index of content validity of the final version

The S-CVI equaled $92.38 \%$ as shown in table (3).

Table (3): Item index of content validity of the final version.

\begin{tabular}{|c|c|c|}
\hline Items & $\begin{array}{c}\text { Number of very relevant } \\
\text { responses }\end{array}$ & I-CVI \\
\hline Item (1) & $\mathbf{8}$ & $\mathbf{8 9 \%}$ \\
\hline Item (2) & $\mathbf{8}$ & $\mathbf{8 9 \%}$ \\
\hline Item (3) & $\mathbf{9}$ & $\mathbf{1 0 0 \%}$ \\
\hline Item (4) & $\mathbf{8}$ & $\mathbf{8 9 \%}$ \\
\hline Item (5) & $\mathbf{9}$ & $\mathbf{1 0 0 \%}$ \\
\hline Item (6) & $\mathbf{8}$ & $\mathbf{8 9 \%}$ \\
\hline Item (7) & $\mathbf{9}$ & $\mathbf{1 0 0 \%}$ \\
\hline Mean & $\mathbf{8 . 4}$ & $\mathbf{9 3 . 7 \%}$ \\
\hline
\end{tabular}


a) Expert proportion of relevance of the final version

The mean of the proportion of relevance (relevant responses) equaled $93.7 \%$ as shown in table (4).

Table (4): Expert proportion of relevance of the final version.

\begin{tabular}{|c|c|c|}
\hline Expert No & $\begin{array}{c}\text { Number of very Relevant } \\
\text { responses }\end{array}$ & Proportion of very relevant \\
\hline 1 & 6 & $\mathbf{6 5 . 7 \%}$ \\
\hline 2 & 7 & $\mathbf{6 0 \%}$ \\
\hline 3 & 6 & $\mathbf{8 5 . 7 \%}$ \\
\hline 4 & 7 & $\mathbf{1 0 0 \%}$ \\
\hline 5 & 7 & $\mathbf{1 0 0 \%}$ \\
\hline 6 & 6 & $\mathbf{8 5 . 7 \%}$ \\
\hline 7 & 6 & $\mathbf{8 5 . 7 \%}$ \\
\hline $\mathbf{8}$ & $\mathbf{7}$ & $\mathbf{1 0 0 \%}$ \\
\hline Mean & $\mathbf{7}$ & $\mathbf{9 3 . 6 \%}$ \\
\hline
\end{tabular}

\section{Patients Results:}

- Answers of first item

Missed data: 3

Valid data: 147

The descriptive statistics of answers of the first item showed that 78 sheets (representing 52\%) reported the first response, 48 sheets (representing 32\%) reported the second response, and 21 sheets (representing 14\%) reported the third response.

\section{- Answers of second item}

Missed data: 15

Valid data: 135

The descriptive statistics of answers of the second item showed that 33 sheets (representing 22\%) reported the first response, 99 sheets (representing 66\%) reported the second response, 3 sheet (representing $2 \%$ ) reported the third response.

\section{- Answers of third item}

Missed data: 0

Valid data: 150

The descriptive statistics of answers of the third item showed that 27 sheets (representing 18\%) reported the first response, 42 sheets (representing 28\%) reported the second response, 57 sheets (representing $38 \%$ ) reported the third response, and 24 sheets (representing 16\%) reported the fourth response.

\section{- Answers of fourth item}

Missed data: 0

Valid data: 150

The descriptive statistics of answers of the fourth item showed that 15 sheets (representing 10\%) reported the first response, 18 sheets (representing 12\%) reported the second response, 111 sheets 
(representing 74\%) reported the third response, 6 sheets (representing $4 \%$ ) reported the fourth response.

\section{- Answers of fifth item}

Missed data: 3

Valid data: 147

The descriptive statistics of answers of the fifth item showed that 9 sheets (representing 6\%) reported the first response, 57 sheets (representing 38\%) reported the second response, 36 sheets (representing $24 \%$ ) reported the third response, 45 sheets (representing 30\%) reported the fourth.

\section{- Answers of sixth item}

Missed data: 0

Valid data: 150

The descriptive statistics of answers of the sixth item showed that 6 sheets (representing 4\%) reported the first response, 9 sheets(representing $6 \%$ ) reported the second response, 42 sheets (representing 28\%) reported the third response, 21 sheets (representing 14\%) reported the fourth response and 72 sheets (representing 48\%) reported the fifth.

\section{- Answers of seventh item}

Missed data: 3

Valid data: 147

The descriptive statistics of answers of the seventh item showed that 12 sheets (representing 8\%) reported the first response, 39 sheets (representing 26\%) reported the second response, 12 sheets (representing $8 \%$ ) reported the third response, 84 sheets (representing 56\%) reported the fourth response.

\section{Correlation coefficients (spearman's rank correlations)}

Regarding that the two-tailed value of $\mathrm{P}$ is 0.01 , Spearman's rank correlations were calculated as shown in table (5).

Table (5): Spearman's rank correlations coefficients

\begin{tabular}{|c|c|c|c|}
\hline Item No & R value & Correlation strength & $\begin{array}{c}\text { Results of test } \\
\text { regarding association } \\
\text { between pre- and post- } \\
\text { test }\end{array}$ \\
\hline 1 & $\mathbf{0 . 1 9}$ & Weak & Non-significant \\
\hline 2 & $\mathbf{0 . 5 2}$ & Moderate & Significant correlation \\
\hline 3 & $\mathbf{0 . 5 4}$ & Moderate & Significant correlation \\
\hline 4 & $\mathbf{0 . 3 3}$ & Weak & Non-significant \\
\hline $\mathbf{5}$ & $\mathbf{0 . 4 7}$ & Moderate & Significant correlation \\
\hline 7 & $\mathbf{0 . 7 9 8}$ & Strong & Significant correlation \\
\hline
\end{tabular}

R: Spearman's rank correlation

\section{DISCUSSION}

The Arabic version of jebsen taylor hand function test has excellent face validity as scale index of clarity equaled $100 \%$, and the mean of proportion of clearance (clear responses) equaled $100 \%$, also it has excellent 
content validity as S-CVI equaled $92.38 \%$, and the mean of the proportion of very relevance (very relevant responses) equaled $92.38 \%$.

The Arabic version of jebsen taylor hand function test has high feasibility because the scale items were filled out by $100 \%$ in all sheets and it needed three minutes or less to be answered in about $75 \%$ of all sheets, also it needed less than 5 minutes to be answered in about $99 \%$ of all sheets.

The Arabic version of jebsen taylor hand function test has good internal consistency and good test retest reliability as Cronbach's alpha equaled0.598 (ranged from 0.487 to 0.660).. However, Spearman's rank correlation coefficients between test and retest results were statistically significant (item 1: 0.19 , item 2: 0.52 , item 3: 0.54 , item 4: 0.33 , item 5: 0.47, item 6: 0.789, item 7: 0.50). According to (George and Mallery, 2003) $\alpha$ between 0.7 and 0.9 is referred as good internal consistency, also Spearman's rank correlation coefficient between 0.7 and 0.9 is referred as good test retest reliability and Spearman's rank correlation coefficient between 0.6 and 0.7 is referred as acceptable test retest reliability.

\section{SUMMARY}

This study was designed to test the face validity, the content validity, the feasibility, the internal consistency reliability and the test retest reliability of Arabic-language version of jebsen taylor hand function test to measure the hand function level in normal people. Two expert panels (each consists of nine experts)and 150 normal people participated in this study, this study was conducted in outpatient clinics of Al-Kasr AlAini Hospital and outpatient clinic of Faculty of Physical Therapy, Cairo University. Forward translation, development of preliminary initially translated version, backward translation, development of the pre-final version and testing of pre-final version using experts then testing of the final version on patients was done.

\section{CONCLUSION}

The results obtained from the current study and the discussion that followed it can lead to concluding that Arabic-language version of the jebsen taylor hand function test has face and content validity, feasibility and internal consistency and test retest reliability enough to measure the physical function in normal people.

\section{IMPLEMENTATIONS}

Depending on the findings of this study, the Arabic-language version of jebsen taylor hand function test scale could be used in research and clinical setting for physical therapy and other professionals to measure the hand function in normal people as it is valid, feasible and reliable tool.

\section{RECOMMENDATION}

The results of this study indicated need to consider the following recommendations: 
1. Further studies should be conducted to establish the preliminary psychometrics of the Arabic-language version of jebsen taylor hand function test with bilingual participants.

2. Further studies should be conducted to establish the full psychometric properties (construct and criterion validity) of Arabic-language version of jebsen taylor hand function test in a sample of the target population of interest.

3. Further studies should be conducted to translate, adapt and validate other assessment instruments for hand function.

4. Further studies should be conducted to translate, adapt and validate other assessment instruments for physical function in different health conditions.

\section{REFERENCES}

Białkowska, J. ; B. Juśkiewicz-Swaczyna and M. Andrzejczak (2020) 'Using the Jebsen-Taylor test in patients after radial bone fracture', Advances in Rehabilitation, 35(1): 24-31.

Culicchia, G. and et al. (2016) 'Cross-Cultural Adaptation and Validation of the Jebsen-Taylor Hand Function Test in an Italian Population'. Hindawi Publishing Corporation, 2016. doi: 10.1155/2016/8970917.

Fabbri, B. and et al. (2021) 'A systematic review of the psychometric properties of the Jebsen-Taylor Hand Function Test (JTHFT)', Hand Surgery and Rehabilitation. Elsevier.

George, D. and P. Mallery (2003) 'Reliability analysis', SPSS for Windows, step by step: a simple guide and reference, 14th edn. Boston: Allyn \& Bacon, pp. 222-232.

Hackel, M. E. and et al. (1992) 'Changes in hand function in the aging adult as determined by the Jebsen Test of Hand Function', Physical Therapy. Oxford University Press, 72(5): 373-377.

Jebsen, R. H. and et al. (1969) 'An objective and standardized test of hand function.', Archives of physical medicine and rehabilitation, 50(6): 311-319.

Kamel, F.A.H. and M. A. Basha, (2021) 'Effects of Virtual Reality and Task-Oriented Training on Hand Function and Activity Performance in Pediatric Hand Burns: A Randomized Controlled Trial', Archives of Physical Medicine and Rehabilitation. Elsevier.

Lee, S.M. (2014) 'The Difference of Hand Functions in Dominant Hand Types', Journal of Korean Clinical Health Science. The Korean Society of Clinical Health Science, 2(2): 119-125.

Lim, Y.X. and S.C. Chai (2020) 'Standardized translated instruction versus spontaneously translated instruction: Test-retest and interrater reliability of a hand function test', Journal of Hand Therapy. Elsevier, 33(4): 553-561. 
Panuccio, F. and et al. (2021) 'Internal consistency and validity of the Italian version of the Jebsen-Taylor hand function test (JTHFT-IT) in people with tetraplegia', Spinal cord. Nature Publishing Group, 59(3): 266-273.

Priya, B.A. and S.P. Desai (2011) 'Normative data of Jebsen Taylor Hand Function Test [modified version] on Indian Population', Physiotherapy and Occupational Therapy, 5(1): 24.

Rhee, H. I J. Yu and S. Kim (2011) 'Influence of compression types on hand function: a preliminary investigation', Journal of Physical Therapy Science. The Society of Physical Therapy Science, 23(3): 477-480.

Takla, M.K.N. ; E. A. K. Mahmoud and N.Abd El-Latif (2018) 'Jebsen Taylor Hand Function test: Gender, dominance, and age differences in healthy Egyptian population', Bulletin of Faculty of Physical Therapy. Springer, 23(2): 85-93.

Tofani, M. and et al. (2020) "Examining reliability and validity of the Jebsen-Taylor hand function test among children with cerebral palsy', Perceptual and motor skills. SAGE Publications Sage CA: Los Angeles, CA, 127(4): 684-697.

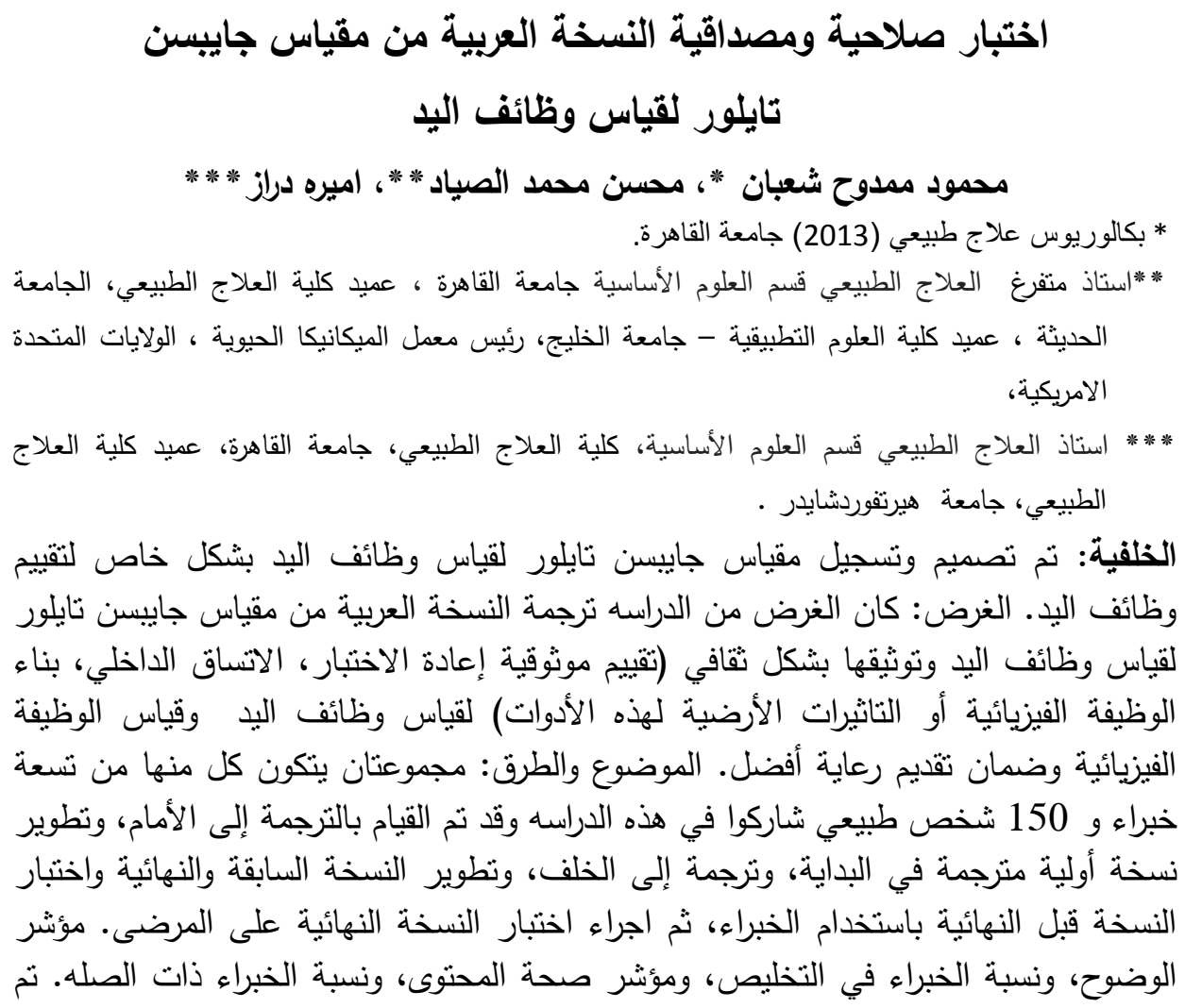


استخدام إحصائيات وصفية ومؤشر العناصر المفقودة والوقت المستغرق للإجابة على المقياس،

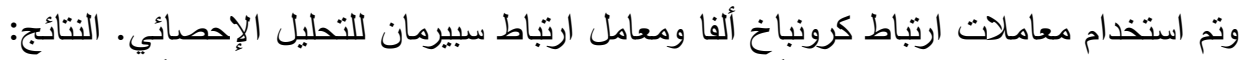

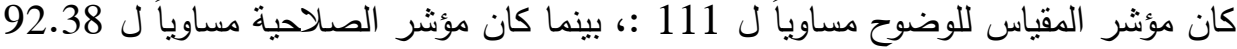

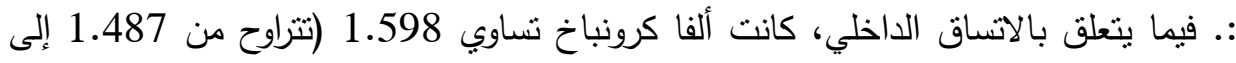

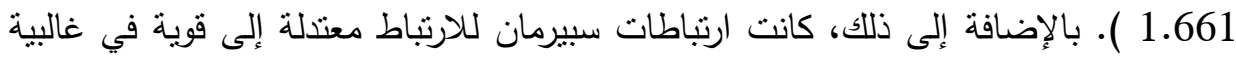

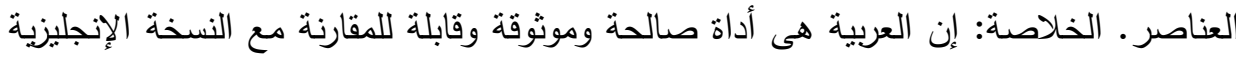

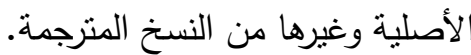
الكلمات المفتاحية :المصداقية- اللغة العربية. 